\title{
Selection of superior genotype of sweet-potato in Indonesia based on stability and adaptability
}

\author{
Yohanis Amos Mustamu ${ }^{1}$, Koko Tjintokohadi², Wolfgang J. Grüneberg ${ }^{3}$, Agung Karuniawan¹, \\ and Dedi Ruswandi ${ }^{{ }^{*}}$ \\ ${ }^{1}$ University of Padjadjaran (Unpad), Faculty of Agriculture, 45363 Sumedang, Indonesia. \\ *Corresponding author (d.ruswandi@unpad.ac.id). \\ ${ }^{2}$ International Potato Center-Regional Office for East, Southeast Asia and the Pacific (CIP-ESEAP), 40263 Lembang-Bandung, Indonesia. \\ ${ }^{3}$ International Potato Center (CIP), 1895 La Molina, Lima, Peru.
}

Received: 2 April 2018; Accepted: 4 September 2018; doi:10.4067/S0718-58392018000400461

\begin{abstract}
Sweet-potato (Ipomoea batatas [L.] Lam.) is the $3^{\text {rd }}$ most important root and tuber plant in the world, after potatoes and cassava. The knowledge of the structure of Genotype $\times$ Environment interaction (GEI) could assist in the development of cultivars of sweet-potato. The objective of this research was to select superior sweet-potato genotypes in Indonesia based on Finlay-Wilkinson regression, additive main effect and multiplicative interaction (AMMI) analysis, AMMI stability value (ASV), and Genotype plus Genotype $\times$ Environment (GGE) biplot methods. Genetic materials evaluated in this research were 10 Indonesian superior genotypes developed by the Plant Breeding and Seed Technology Lab., Faculty of Agriculture, University of Padjadjaran, Bandung. The research was arranged in randomized block design, with 16 genotypes as treatments. Data analysis of the yield characters was performed by using combined variance analysis: Finlay-Wilkinson regression, ASV, AMMI, and GGE Biplot. The GEI significantly influenced the tested genotypes at three sites. However, they did not show any significant differences in the GEI. Ayamurasaki, Beniazuma, Awachy2, 15(112), Awachy4, Awachy5, 80(109), 54(160), 35(180) were specific adaptation genotypes of marginal land based on Finlay-Wilkinson analysis; whereas, Rancing, AC Putih, Ayamurasaki, Naruto Kinotoki, Awachy1, Awachy2, 15(112), Awachy4, 57(97), 80(109), 54(160), 68(120) and 35(180) performed as stable genotypes based on ASV. Ayamurasaki, Naruto Kinotoki, Awachy1, Awachy2, 57(97), 80(109) and 68(120) were stable genotypes based on AMMI analysis. However, based on GGE Biplot analysis Ayamurasaki, Awachy1, 80 (109) and 68 (120) were stable genotypes. ASV analysis provided effective stable genotype selections of $87.50 \%$ greater than other stability methods. Ayamurasaki, Awachy1, 80(109) and 68(120) were stable genotypes based on AMMI, ASV, and GGE biplot analysis.
\end{abstract}

Key word: AMMI, ASV, GGE, Ipomoea batatas, specific genotype.

\section{INTRODUCTION}

Sweet-potato grow and develop well in various environments both in optimal and sub optimal conditions. Sweet-potato (Ipomoea batatas [L.] Lam) is the $3^{\text {rd }}$ most important root and tuber plant in the world, after potatoes and cassava (Naidoo et al., 2016). Sweet-potato is a root crop that grows almost worldwide and is adapted to diverse environments conditions (Caliskan et al., 2007; Hongyu et al., 2014; Niringiye et al., 2014; Andrade et al., 2016; Gurmu et al., 2017); this is why it can be found from the lowland up to the plateau. They are used as an alternative food for rice.

In some areas of Indonesia, sweet-potatoes are used as staple food as well as an alternative food other than rice and corn. According to Mwololo et al. (2009) and Gurmu (2017), sweet potato is ranked as the seventh importance crop in the world. Sweet-potatoes are important because of its carbohydrate and nutrient content. They are also used for various 
processed foods and industrial raw materials, such as foodstuffs, feed ingredients, and bioethanol materials (Karuniawan et al., 2012; Grüneberg et al., 2015; Waluyo et al., 2015). They also contain important nutrients for pro vitamin A such as $\beta$-carotene. Cultivation of sweet-potatoes in areas with high levels of vitamin A deficiency is an alternative to solve the problem. Andrade et al. $(2009 ; 2016)$ reported that vitamin A deficiency commonly occurs in women and children.

Genotype and environmental interactions (GEI) are associated with the performance of varieties that show stability when planted in different environments. Ruswandi et al. (2008) reported selection of high yielding varieties based on multi environment testing. This is very important for countries with diverse bio-geophysical patterns. The knowledge of the structure of GEI could assist in the development of cultivars of sweet-potato (Andrade et al., 2016). According to Roostaei et al. (2014), the GEI factor is an important issue faced by plant breeders in crop breeding programs. GEI is essential for the acquisition of new and superior bulbs as reported by many researchers (Niringiye et al., 2014; Hongyu et al., 2014). This led to the need for adaptation and stability tests to get the high quality and adaptive genotypes under different environmental conditions. New superior varieties to be selected in multi-environment tests are expected to be potentially stable and uniform even though grown in different environments.

There are two methods for stability and adaptability evaluation, namely: univariate and multivariate. Some well-known methods include regression, additive main effect and multiplicative interaction (AMMI) and Genotype plus Genotype $\times$ Environment (GGE) Biplot methods (Finlay and Wilkinson, 1963; Yan et al., 2007; Hongyu et al., 2014). Several researchers also performed stability and adaptability evaluations by combining several test methods (Adebola et al., 2013; Kivuva et al., 2014; Chalwe et al., 2017). The AMMI and GGE biplot analysis are important methods in analyzing GEI that assist plant breeders to identify and select the superior genotypes in certain environments (Adebola et al., 2013; Amare et al., 2014; Kivuva et al., 2014). AMMI stability value (ASV) is the distance from the coordinate point to the origin in the two-dimensional scatter of the IPCA1 value against the IPCA2 value in the AMMI model (Purchase, 1997). AMMI biplot is needed in describing test sites and genotype performance at the test sites (Kivuva et al., 2014). GGE biplot is built by plotting the major component values (PC1) of genotypes and environments against their respective scores for the second major component (PC2) generated from environment-oriented singular value decomposition (SVD) or environmental standards (Yan et al., 2007). Thus, genotype and environmental interactions have an influence on cultivar selection and recommendations.

The aim of the study was to select stable and adaptable sweet-potatoes genotypes based on Finlay-Wilkinson Regression method, AMMI stability value (ASV), AMMI, and GGE biplot.

\section{MATERIALS AND METHODS}

Genetic material. Ten new superior genotypes and 10 commercial genotype controls were evaluated in this study. They were genotypes derived from breeding materials of Plant Breeding and Seed Technology Lab., Faculty of Agriculture, University of Padjadjaran, Bandung, Indonesia.

Field evaluation. The research was arranged in a randomized block design, with three replicates and 16 test genotypes as the treatment to obtain 48 experimental units. Genetic material was planted in single ridges, $5 \mathrm{~m}$ long, and $25 \mathrm{~cm}$ spacing in ridges and $75 \mathrm{~cm}$ between ridges. The observed variable was the yield $\left(\mathrm{kg} \mathrm{plot}^{-1}\right)$. Data analysis was performed on yield character $\left(\mathrm{kg} \mathrm{plot}^{-1}\right.$ ) by using SAS 9.1.3 (SAS Institute, Cary, North Carolina, USA), PBStat.com (Central Library of Bogor Agricultural University, Bogor, Indonesia), PBTools.

Statistical model for combined ANOVA over environments:

$$
Y_{i j k l}=\mu+G_{i}+E_{j}+G E_{i j}+R_{k(j)}+B_{l(k)}+\varepsilon_{i j k l}
$$

where $Y_{i j k l}$ is observed value of genotype $\mathrm{i}$ in block 1 and replicate $\mathrm{k}$ of environment $\mathrm{j}, \mu$ is grand mean, $G_{i}$ is effect of genotype i, $E_{j}$ is environment or location effect, $G E_{i j}$ is the interaction effect of genotype i with environment $\mathrm{j}, R_{k(j)}$ is the effect of replicate $\mathrm{k}$ in environment $\mathrm{j}, B_{l(k)}$ is the effect of block 1 in replicate $\mathrm{k}, \varepsilon_{i j k l}$ is error (residual) effect of genotype $\mathrm{i}$ in block 1 and replication $\mathrm{k}$ of environment $\mathrm{j}$.

Regression coefficient (b1) (Finlay and Wilkinson, 1963) to stability was calculated based on:

$$
A=b o+b l x l
$$

where $A$ is the mean of an individual cultivar for a given trait, $b o$ is the Y-axis intercept, $b l$ is the linear regression coefficient or slope, and $x l$ is the environmental mean (mean from all cultivars within an environment) for a given trait. 
AMMI's stability value (ASV) was calculated (Purchase, 1997) based on:

$$
\text { AMMI Stability Value }(A S V)=\sqrt{\left.\left[\frac{I P C A 1 \text { sum of square }}{[\text { IPCA } \text { sum of square }} \text { (IPCA1 score }\right)\right]^{2}+[(\text { IPCA1 score })]^{2}}
$$

where IPCAl is interaction principal component analysis axis 1; IPCA2 is interaction principal component analysis axis 2.

The linear model of genotype and environmental interaction analysis in AMMI analysis in Gauch and Zobel (1996) is as follows:

$$
Y_{i j r}=\mu+g_{i}+e_{j}+\sum_{k=1}^{x} \lambda_{k} \alpha_{i k} \gamma_{j k}+\varepsilon_{i j r}
$$

where $Y_{i j}$ is observation of the $\mathrm{r}^{\text {th }}$ replicate of $\mathrm{i}^{\text {th }}$ genotype in the $\mathrm{j}^{\text {th }}$ environment, $\mu$ is the overall mean, $g_{i}$ is main effect of the $\mathrm{i}^{\text {th }}$ genotype $e_{j}$ is main effect of the $\mathrm{j}^{\text {th }}$ environment, $x$ is matrix rank of $\{\mathrm{ge}\}_{\mathrm{ij}}, \lambda_{k}$ is the singular value for principal component $\mathrm{k}, \alpha_{i k}$ is the eigenvector score for genotype $\mathrm{i}$ and component $\mathrm{k}, \gamma_{j k}$ is the eigenvector score for environment $\mathrm{j}$ and component $\mathrm{k}, \varepsilon_{i j}$ is error term.

The model for a Genotype plus Genotype $\times$ Environment (GGE) bi-plot based on singular value decomposition (SVD) of $t$ principal components is:

$$
\bar{Y}_{i j}-\mu_{i}-\beta_{j}=\sum_{k=1}^{t} \lambda_{k} \alpha_{i k} \gamma_{j k}+\varepsilon_{i j}
$$

where $\bar{Y}_{i j}$ is the performance of genotype $\mathrm{i}$ in environment $\mathrm{j}, \mu_{i}$ is the grand mean, $\beta_{j}$ is the main effect of environment $\mathrm{j}, k$ is the number of principal components; $\lambda_{k}$ is singular value of the $\mathrm{k}^{\text {th }}$ principal components; and $\alpha_{i k}$ and $\gamma_{j k}$ are the scores of $\mathrm{i}^{\text {th }}$ genotype and $\mathrm{j}^{\text {th }}$ environment, respectively for principal components $\mathrm{k} ; \varepsilon_{i j}$ is the residual associated with genotype $\mathrm{i}$ in environment $\mathrm{j}$.

\section{RESULTS AND DISCUSSION}

The results of the combined analysis for the yield of 16 superior sweet potato genotypes in Indonesia at 3 sites showed that the main effect of genotype and its interaction with environment had significant effect on the probability of 0.0000 and 0.0006 (Table 1). This indicated that sweet-potatoes yield is influenced by genotype and GEI. The significant factor of sweet-potato yields is described by the genotypes, followed by the GEI. Hence, the yield of sweet-potato in Indonesia is greatly determined by genotype and genotype and environment interaction. Table 1 reveals that the genotype and environment interaction produced significant effect on the yield of sweet-potato crops. Some researchers also reported that GEI is significant for the multi-environment test (Tekalign, 2007; Adebola et al., 2013; Thiyagu et al., 2013; Amare et al., 2014; Hongyu et al., 2014; Chalwe et al., 2017; Gurmu et al., 2017). This indicates that certain genotypes will grow well in specific environments but not in all different environments. Genotype of Rancing performed the best appearance in Sumedang $\left(23.85 \mathrm{~kg} \mathrm{plot}^{-1}\right)$ and Bandung (47.96 kg plot ${ }^{-1}$ ), while Beniazuma was the best genotype at Karawang (48.57 kg plot ${ }^{-1}$ ). Awachy2 had the lowest performance in Sumedang and Karawang, whereas Awachy4 had the lowest appearance at Bandung. Low yield genotypes based on interactions showed the existence of an interaction between genotype and environment.

Phenotypically, 16 sweet-potato genotypes that performed the best response according to least significantly different (LSD) test (Table 2) are Rancing (47.95 $\mathrm{kg} \mathrm{plot}^{-1}$ ) and Kriting Maja (39.84 kg plot ${ }^{-1}$ ); while the lowest response were presented by Naruto kinotoki (10.68 $\left.\mathrm{kg} \mathrm{plot}^{-1}\right)$, Awachy2 $\left(9.80 \mathrm{~kg} \mathrm{plot}^{-1}\right)$, Awachy4 (13.91 kg plot $\left.{ }^{-1}\right)$ and 35(180) (13.25 kg plot $\left.{ }^{-1}\right)$.

Table 1. Combined ANOVA for superior root yield of sweetpotatoes in Indonesia.

\begin{tabular}{lrrrc}
\hline Source & df & \multicolumn{1}{c}{ SS } & \multicolumn{1}{c}{ MS } & F-count \\
\hline Location & 2 & 397.71 & 198.86 & $2.03^{\text {ns }}$ \\
Replication $\times$ Location & 6 & 586.52 & 97.75 & $0.78^{\text {ns }}$ \\
Genotype & 15 & 16049.35 & 1069.96 & $3.50^{* *}$ \\
Genotype $\times$ Location & 30 & 9164.74 & 305.49 & $2.45^{* *}$ \\
Error & 90 & 11223.13 & 124.70 & \\
Corrected total & 143 & 37421.45 & & \\
\hline
\end{tabular}

**Significant at the 0.01 probability level; ns: nonsignificant; df: degrees of freedom; SS: sum of squares; MS: mean sum of squares. 
Table 2. Mean yield, stability and adaptability in three locations at Indonesia based on Finlay and Wilkinson regression methods.

\begin{tabular}{rllrl}
\hline $\mathrm{Nr}$ & Genotype & Average & $\mathrm{b}_{\mathrm{i}}$ & \\
\hline 1 & Rancing-v1 & $47.95 \mathrm{a}$ & 6.66 & Specific adaptation \\
2 & Ac Putih-v2 & $32.12 \mathrm{abc}$ & 1.40 & Specific adaptation \\
3 & Ayamurasaki-v3 & $20.61 \mathrm{bcd}$ & 0.26 & Specific adaptation to marginal environment \\
4 & Beniazuma-v4 & $33.43 \mathrm{ab}$ & -4.24 & Specific adaptation to marginal environment \\
5 & Naruto Kinotoki-v5 & $10.68 \mathrm{~d}$ & 2.73 & Specific adaptation \\
6 & Kriting maja-v6 & $39.84 \mathrm{a}$ & 7.83 & Specific adaptation \\
7 & Awachy1-v7 & $19.93 \mathrm{bcd}$ & 1.76 & Specific adaptation \\
8 & Awachy2-v8 & $9.80 \mathrm{~d}$ & -0.60 & Specific adaptation to marginal environment \\
9 & 15(112)-v9 & $22.13 \mathrm{bcd}$ & -0.04 & Specific adaptation to marginal environment \\
10 & Awachy4-v10 & $13.91 \mathrm{~d}$ & -2.71 & Specific adaptation to marginal environment \\
11 & Awachy5-v11 & $19.73 \mathrm{bcd}$ & -3.33 & Specific adaptation to marginal environment \\
12 & $57(97)-\mathrm{v} 12$ & $33.01 \mathrm{abc}$ & 1.71 & Specific adaptation \\
13 & 80(109)-v13 & $20.49 \mathrm{bcd}$ & 0.72 & Specific adaptation to marginal environment \\
14 & $54(160)-\mathrm{v} 14$ & $16.45 \mathrm{~cd}$ & -1.75 & Specific adaptation to marginal environment \\
15 & 68(120)-v15 & $20.17 \mathrm{bcd}$ & 7.92 & Specific adaptation \\
16 & 35(180)-v16 & $13.25 \mathrm{~d}$ & -2.31 & Specific adaptation to marginal environment \\
\hline
\end{tabular}

Values with same letter are nonsignificantly different according to LSD.

\section{Selection genotypes of sweet potato marginal adaptation based on Finlay and Wilkinson regression}

Finlay and Wilkinson regression coefficient showed that specific adaptation's genotypes for the productive environment are Rancing, AC-putih, Narutokinotoki, Kriting maja, 57(97) and 68(120), whilst those at the marginal environment are Ayamurasaki, Beniazuma, Awachy2, 15(112), Awachy4, Awachy5, 80(109), 54(160) and 35(180). This shows that there are no varieties having broad adaptation in the three test sites based on the Finlay-Wilkinson method. Genotypes with specific adaptability at marginal environments are able to achieve maximum results in poor growing conditions, whereas genotypes that having a specific adaptation to the productive environment are unable to increase yields in the marginal environments. Varieties with broad adaptation produce high yields throughout the environment, while varieties with specific adaptation had high yields in certain environments (Yan and Tinker, 2006; Mwololo et al., 2009). Carvalho et al. (2016) state that the regression method benefit was to interpret specific genotypes but lacks information about the whole test environment. The use of this method will be difficult to apply in Indonesia considering it has a variety of bio-geophysics. This is because the determination of adaptive genotype is only based on the average value of different genotypes due to environmental differences.

\section{Selection for stable genotype of sweet potato based on AMMI analysis}

The results of AMMI analysis indicated that IPCA1 and IPCA2 produced small values both in positive and negative. The values of IPCA1 and IPCA2 were relatively low and high, respectively. This suggests that the tuber weight was more affected by environment than genetics. The higher the values of IPCA either positive or negative, the more specific genotype adaptation to a particular environment (Farshadfar, 2008; Adebola et al., 2013; Kivuva et al., 2014). Roostaei et al. (2014) explained that AMMI model using the ANOVA (additive model) to characterize the main effects of genotype and environment as well as to analyze the key components for characterizing their interaction (IPCA). Furthermore, Faria et al. (2017) state that the stability interpretation by the AMMI method is based on the distance up to zero of the point value representing hybrids and the environment. This means that IPCA values of some tested genotypes can produce high yields when growing in a productive environment and some are able to achieve high yields when growing in a specific environment.

Based on the ASV genotype method (Table 3) that those have a low value is found more stable. The study showed that there were 14 genotypes of sweet-potato that had the ASV value below one. Those classified as stable genotypes, are 80 (109), Naruto Kinotoki, Ayamurasaki, Awachy2, AC Putih, 35(180), 54(160), 15(112), Rancing, Beniazuma, Awachy1, Awachy4, Kriting maja, 68 (120). The stable genotype was not affected by the environment. The stable genotypes are in Sumedang, Bandung, and Karawang. On the other hand, unstable genotypes may be proposed as site-specific genotypes for both tolerant and productive environments. The genotype is stable when the ASV value is close to zero (Tumuhimbise et al., 2014; Nduwumuremyi et al., 2017). According to Farshadfar (2008), ASV is the 0 distance in 2 scatter dimension value of IPCA1 to IPCA2. This means that IPCA1 supplied the highest effect of test genotype stability value. 
Table 3. IPCA1 and IPCA2 value of sweet-potatoes genotype in three locations.

\begin{tabular}{lcrrl}
\hline Genotype & Average & IPCA1 & IPCA2 & ASV \\
\hline Rancing & 47.95 & -0.28 & 0.01 & 0.51 \\
Ac Putih & 32.12 & -0.09 & -0.14 & 0.30 \\
Ayamurasaki & 20.61 & -0.02 & -0.12 & 0.20 \\
Beniazuma & 33.43 & 0.29 & 0.05 & 0.54 \\
Naruto Kinotoki & 10.68 & -0.05 & 0.06 & 0.15 \\
Kriting maja & 39.84 & -0.33 & 0.04 & 0.60 \\
Awachy1 & 19.94 & -0.04 & 0.31 & 0.56 \\
Awachy2 & 9.80 & 0.02 & -0.12 & 0.21 \\
15(112) & 22.13 & 0.17 & 0.22 & 0.50 \\
Awachy4 & 13.92 & 0.28 & 0.16 & 0.58 \\
Awachy5 & 19.73 & 0.18 & -0.79 & 1.47 \\
57(97) & 33.01 & -0.03 & 0.79 & 1.43 \\
80(109) & 20.49 & -0.01 & -0.05 & 0.09 \\
54(160) & 16.45 & 0.04 & -0.18 & 0.33 \\
68(120) & 20.17 & -0.20 & 0.28 & 0.62 \\
35(180) & 13.25 & 0.08 & -0.16 & 0.32 \\
Sumedang & & -0.46 & 0.25 & \\
Bandung & & -0.06 & 0.42 & \\
Karawang & & 0.52 & 0.17 & \\
\hline
\end{tabular}

IPCA1: Interaction component analysis 1, IPCA2: interaction component analysis 2, ASV: AMMI stability value.

AMMI2 biplot results (Figure 1) show that there are stable genotypes in all tested sites and there are specific genotypes at particular location. The stable genotype is indicated by its location close to the axis. The location-specific genotype is far from the axis but close to the location line. In the Figure 1, the broadly adapted genotypes based on the tuber weight

Figure 1. AMMI biplot for sweet-potato yield in three environments.

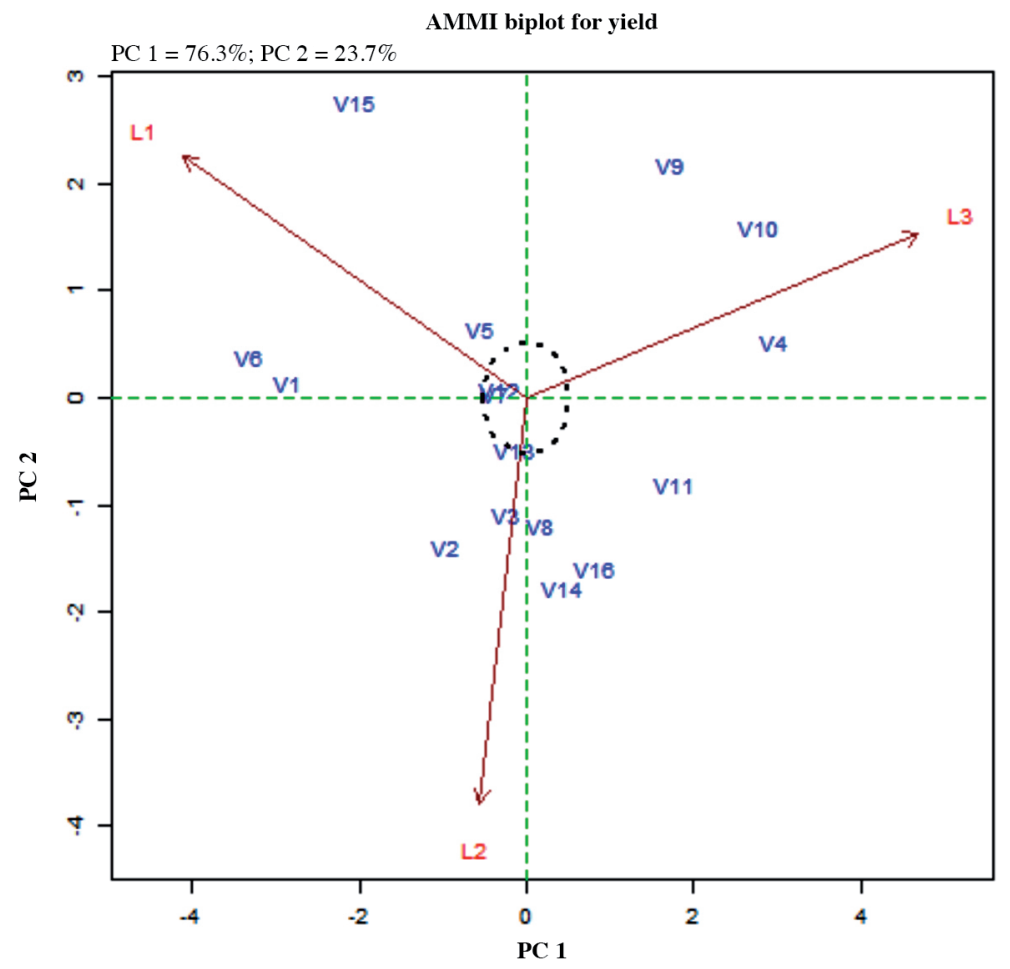

V1: Rancing, V2: Ac Putih, V3: Ayamurasaki, V4: Beniazuma, V5: Naruto Kinotoki, V6: Kriting Maja, V7: Awachy1, V8: Awachy2, V9: 15(112), V10: Awachy4, V11: Awachy5, V12: 57(97), V13: 80(109), V14: 54(160), V15: 68(120), V16: 35(180), L1: Sumedang, L2: Bandung, L3: Karawang. 
characteristics per plot are Awachy1, 57(97), and 80(109). Beniazuma and Awachy4 were found to have local specific adaptation at Karawang regency, while Figure 1 shows no specific genotype location at Sumedang and Bandung. This shows the different response of the tested genotypes against environment differential where it produced the good average results in certain environments but not in different environments. The AMMI model is better than the Finlay-Wilkinson regression because the genotype and environmental interaction patterns are bilinear by mapping the environment and genotypes simultaneously using the biplot model. Gurmu (2017) stated that stability analysis helps to identify the type of adaptable genotype. Adebola et al. (2013) state that the AMMI Model is an important technique to observe the interaction in the identification and selection of excellent genotypes in terms of potential outcomes against various or specific environments. AMMI's analysis is a successful model used to study GEI, and it is a combination of ANOVA and major component analysis (PCA) (Mirosavljevic et al., 2014). According to Sa'diyah and Hadi (2016), AMMI analysis is a two-way experimental data analysis technique the main effect of which is additive and multiplicative. Thiyagu et al. (2013) state that AMMI is a multivariate technique widely applied in plant breeding to illustrate the relationship between genotype and environment. Furthermore, Caliskan et al. (2007) suggest the AMMI model combines variance analysis for the main effects of genotype and the environment by analyzing the major components of the interaction between genotypes and environments that approved to understand genotype and environmental interactions.

\section{Selection of adaptive sweet potato genotype based on GGE biplot}

Biplot (Figure 2) describes $85.35 \%$ of the total GGE variation in which PC1 and PC2 were at $67.02 \%$ and $18.33 \%$, respectively. There are six sectors with Beniazuma, Rancing, Kriting Maja, Naruto Kinotoki, Awachy2 and Awachy4 as the peak genotype and has two environment sectors: sector 2 (environment 1 and 2) and sector 3 (environment 3 ). Genotypes 80 (109), Awachy1, Ayamurasaki and 68(120) are stable in three environments. Genotypes Rancing and Kriting Maja are in the same sector and adapt well to environment 1 and environment 2. Beniazuma adapts well to environment 3 . Figure 2 also shows some superior genotypes in the sector but not in the three tested environments.

Figure 2. GGE biplot for sweet-potato yield in three environments.

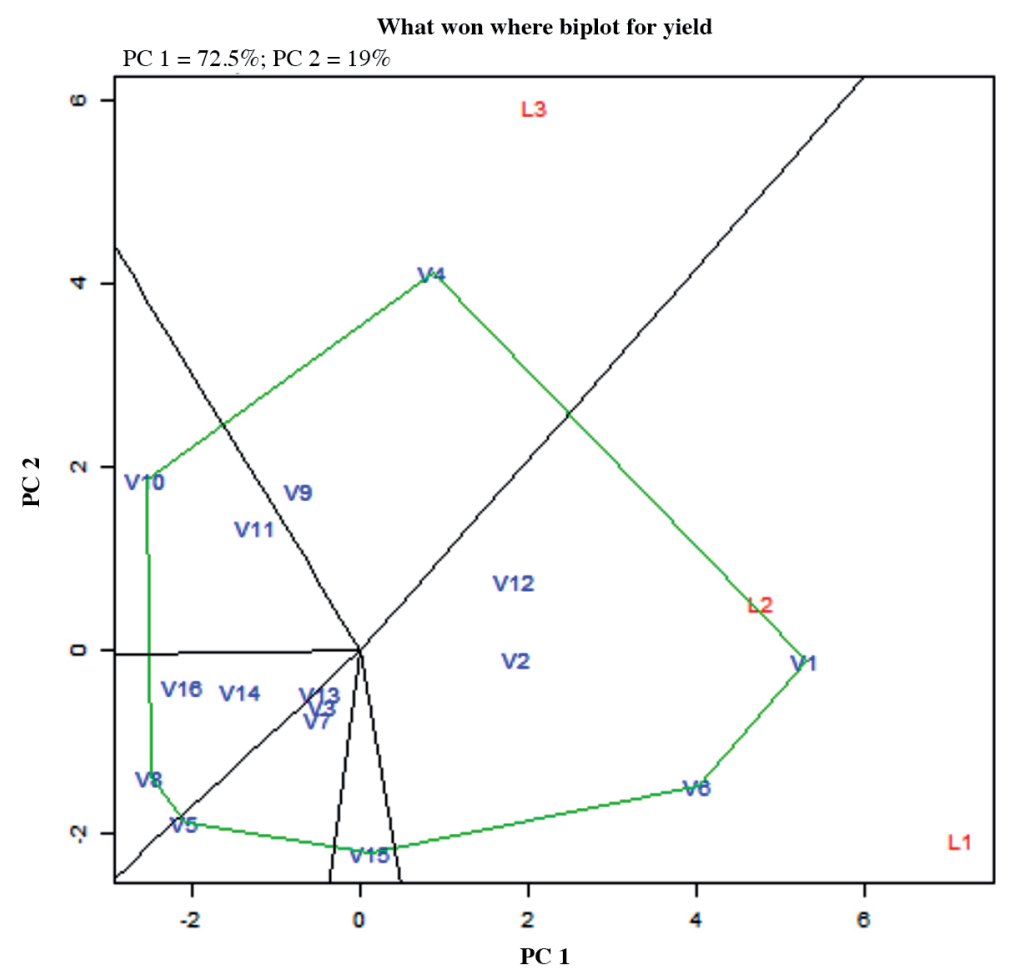

V1: Rancing, V2: Ac Putih, V3: Ayamurasaki, V4: Beniazuma, V5: Naruto Kinotoki, V6: Kriting maja, V7: Awachy1, V8: Awachy2, V9: 15(112), V10: Awachy4, V11: Awachy5, V12: 57(97), V13: 80(109), V14: 54(160), V15: 68(120), V16: 35(180), L1: Sumedang, L2: Bandung, L3: Karawang. 
This shows that the genotypes may still be improved if the numbers of tested locations are added. Biplot analysis is an important multivariate tool that displays results in a graph that is easy to understand (Akinwale et al., 2014). Biplot also show the level of cultivar and environmental stability (Kivuva et al., 2014; Tumuhimbise et al., 2014). Tumuhimbise et al. (2014) stated that Biplot is used to assess the performance and patterns of genotype and environmental interactions. Some researchers found 6-11 sectors on each polygon generated from the GGE test on sweet potato adaptation and stability (Caliskan et al., 2007; Kivuva et al., 2014; Gurmu et al., 2017; Gurmu, 2017). Kivuva et al. (2014) state that the polygon of the GGE biplot reveals the highest yield genotypes for each environment and environmental grouping. Furthermore, Yan et al. (2007) claim that if all the environmental markers fall into one sector, this indicates that a single cultivar has the highest yield in all environments. On the other hand, if environmental markers fall into different sectors, it indicates that different cultivars superior in various sectors. The environments that are located at different sectors show that genotypes in these environments have different yields and classified as specific genotype. Thus, the environment is able to expose a difference among genotypes.

\section{Selection of stable sweet potato genotypes in Indonesia}

Several stable genotypes were selected at three test sites by using Finlay-Wilkinson, AMMI, GGE Biplot, and ASV analysis (Table 4). The stable genotypes cannot be obtained by Finlay-Wilkinson analysis with effectiveness $0 \%$. The selection method with AMMI analysis provides effectivity of stable genotype selection at $18.75 \%$ against the Ayamurasaki, 54(160) and Awachy 4 genotypes. On the other hand, the biplot GGE analysis provides $25 \%$ effectivity of stable genotypes selection against Ayamurasaki, Awachy1, 80(109) and 68(120) genotypes. The selection of stable genotypes based on ASV provides $87.5 \%$ selection effectiveness against Rancing, AC Putih, Ayamurasaki, Naruto Kinotoki, Maja Critic, Awachy1, Awachy2, 15(112), Awachy4, 57(97), 80(109), 54(160), 68(120), 35(180) genotypes.

Based on AMMI, GGE Biplot and ASV analysis, Ayamurasaki were found to be stable in the three tested locations, but Genotypes 54(160) and Awachy4 were stable in three sites according to AMMI and ASV methods. The Awachy1, 80(109) and 68(120) genotypes are stable in the three sites based on GGE Biplot and ASV methods. There is a stable genotype similarity in some selection methods which reflects the ability of each method to assess the genotype stability in some locations. It also shows the superiority of each stability analysis.

Table 4. Stable genotype of sweet-potatoes were selected based on some stability methods.

\begin{tabular}{lcc}
\hline Selection method & $\begin{array}{c}\text { Number of selected } \\
\text { genotypes }\end{array}$ & $\begin{array}{c}\text { Selection } \\
\text { effectiveness }\end{array}$ \\
\hline Finlay-Wilkinson & - & $\%$ \\
AMMI & Ayamurasaki & 0 \\
& $54(160)$ & 18.75 \\
GGE biplot & Awachy 4 & \\
& Ayamurasaki & 25.00 \\
Awachy 1 & \\
AMMI stability value & $80(109)$ & \\
& $68(120)$ & \\
& Rancing & \\
Ac Putih & \\
& Ayamurasaki & \\
& Naruto Kinotoki & \\
Kriting maja & \\
Awachy 1 & \\
Awachy 2 & \\
& $15(112)$ & \\
Awachy 4 & \\
$57(97)$ & \\
$80(109)$ & \\
$54(160)$ & \\
$68(120)$ & \\
& $35(180)$ & \\
\hline
\end{tabular}




\section{CONCLUSION}

This study concludes that the tested sweet-potato genotypes in the three sites were significantly affected by the major effects of genotype and environment interaction but not by the influence of environment and genotype. The Ayamurasaki, Beniazuma, Awachy2,15(112), Awachy4, Awachy5, 80(109), 54(160) and 35(180) are adaptable genotypes in the marginal land based on Finlay-Wilkinson regression. The Ayamurasaki, 5(160) and Awachy4 genotypes are stable genotypes based on AMMI analysis, while Ayamurasaki, Awachy1, 80(109) and 68(120) are stable genotype based on GGE Biplot analysis. Rancing, AC-putih, Ayamurasaki, naruto kinotoki, Awachy1, Awachy2, 15(112), Awachy4, 57(97), 80 (109), 54(160), 68(120) and 35(180) are stable genotypes based on AMMI stability value (ASV). The selection effectiveness of ASV is $87.50 \%$, greater than other stability methods. Ayamurasaki is stable in three tested locations based on AMMI method, GGE Biplot and ASV. Genotypes 54(160) and Awachy4 are stable at three sites based on only two methods, AMMI and ASV. Awachy 1, 80(109) and 68(120) genotypes are stable in the three sites based on GGE Biplot and ASV methods.

\section{ACKNOWLEDGEMENT}

The authors thank the Directorate General Higher Education Republic of Indonesia and University of Padjajaran for the research fund through PUSNAS grant.

\section{REFERENCES}

Adebola, P.O., Shegro, A., Laurie, S.M., Zulu, L.N., and Pillay, M. 2013. Genotype $\times$ environment interaction and yield stability estimate of some sweet potato [Ipomoea batatas (L.) Lam] breeding lines in South Africa. Journal of Plant Breeding and Crop Science 5(9):182-186. https://doi.org/10.5897/JPBCS2013.0387.

Akinwale, R.O., Fakorede, M.A.B., Badu-Apraku, B., and Oluwaranti, A. 2014. Assessing the usefulness of GGE biplot as a statistical tool for plant breeders and agronomists. Cereal Research Communications 42(3):534-546. https://doi.org/10.1556/ CRC.42.2014.3.16.

Amare, B., Abay, F., and Tsehaye, Y. 2014. Evaluation of sweet potato (Ipomea batata L.) varieties for total storage root yield in south. American Journal of Trade and Policy 1(3):27-32.

Andrade, M., Barker, I., Cole, D., Fuentes, S., Grüneberg, W., Kapinga, R., et al. 2009. Unleashing the potential of sweetpotato in Sub-Saharan Africa: Current challenges and way forward. International Potato Center (CIP), Lima, Peru.

Andrade, M.I., Naico, A., Ricardo, J., Eyzaguirre, R., Makunde, G.S., Ortiz, R., et al. 2016. Genotype $\times$ environment interaction and selection for drought adaptation in sweetpotato (Ipomoea batatas [L.] Lam.) in Mozambique. Euphytica 209(1):261-280. https://doi.org/10.1007/s10681-016-1684-4.

Caliskan, M.E., Erturk, E., Sogut, T., Boydak, E., and Arioglu, H. 2007. Genotype × environment interaction and stability analysis of sweetpotato (Ipomoea batatas) genotypes. New Zealand Journal of Crop and Horticultural Science 35(1):87-99. https://doi.org/10.1080/01140670709510172.

Carvalho, B.C.L., Damasceno-Silva, K.J., Rocha, M.M., and Oliveira, G.C.X. 2016. Evolution of methodology for the study of adaptability and stability in cultivated species. African Journal of Agricultural Research 11(12):990-1000. https://doi.org/10.5897/AJAR2015.10596.

Chalwe, A., Chiona, M., Sichilima, S., Njovu, J., Chama, C., Ndhlovu, D., et al. 2017. Genotype Stability index for root yield and tolerance to sweetpotato weevil Cylas puncticolis: A tool for identifying climate smart varieties. Open Agriculture 2:166-174. https://doi.org/10.1515/opag-2017-0017.

Faria, S.V., Luz, L.S., Rodrigues, M.C., Carneiro, J.E. de S., Carneiro, P.C.S., and De Lima, R.O. 2017. Adaptability and stability in commercial maize hybrids in the southeast of the State of Minas Gerais, Brazil. Revista Ciencia Agronomica 48(2):347-357. https://doi.org/10.5935/1806-6690.20170040.

Farshadfar, E. 2008. Incorporation of AMMI stability value and grain yield in a single non-parametric index (GSI) in bread wheat. Pakistan Journal of Biological Sciences 11(14):1791-1796.

Finlay, K.W., and Wilkinson, G. 1963. The analysis of adaptation in a plant breeding program. Australian Journal of Agricultural Research 14(1958):742-754.

Gauch, H.G., and Zobel, R.W. 1996. AMMI analysis of yield trials. p. 85-122. In Kang, M.S., and Gauch, H.G. (eds.) Genotype by environment interaction. CRC Press, Boca Raton, Florida, USA.

Grüneberg, W.J., Ma, D., Mwanga, R.O.M., Carey, E.E., Huamani, K., Diaz, F., et al. 2015. Advances in sweetpotato breeding from 1992 to 2012. In Low, J., Nyongesa, M., Quinn, S., and Parker, M. (eds.) Potato and sweetpotato in Africa: Transforming the value chains for food and nutrition security. CABI International, Boston, Massachusetts, USA. 
Gurmu, F. 2017. Stability analysis of fresh root yield of sweetpotato in Southern Ethiopia using GGE. International Journal of Pure Agricultural Advances 1:1-9.

Gurmu, F., Hussein, S., and Laing, M. 2017. Genotype-by-environment interaction and stability of sweetpotato genotypes for root dry matter, $\beta$-carotene and fresh root yield. Open Agriculture 2:473-485.

Hongyu, K., García-Peña, M., Araújo, L.B. de, and Dias, C.T.S. 2014. Statistical analysis of yield trials by AMMI analysis of genotype $\times$ environment interaction. Biometrical Letters 51(2):89-102. https://doi.org/10.2478/bile-2014-0007.

Karuniawan, A., Waluyo, B., Chandria, W., and Maulana, H. 2012. Pengelolaan dan Pemanfaatan Plasma Nutfah Ubi Jalar Lokal Jawa Barat. Seminar Bulanan Vivat Academia Unpad, Jatinangor. 2 August 1-13.

Kivuva, B.M., Githiri, S.M., Yencho, G.C., and Sibiya, J. 2014. Genotype $\times$ Environment interaction for storage root yield in sweetpotato under managed drought stress conditions. Journal of Agricultural Science 6(10):41-56. https://doi.org/10.5539/jas.v6n10p41.

Mirosavljevic, M., Przulj, N., Bocanski, J., Stanisavljevic, D., and Mitrovic, B. 2014. The application of ammi model for barley cultivars evaluation in multi-year trials. Genetika 46(2):445-454. https://doi.org/10.2298/GENSR1402445M.

Mwololo, J.K., Muturi, P.W., Mburu, M.W.K., Njeru, R.W., Kiarie, N., Munyua, J., et al. 2009. Additive main effects and multiplicative interaction analysis of genotype $\times$ environmental interaction among sweetpotato genotypes. Journal of Animal and Plant Science 2(3):148-155.

Naidoo, S.I.M., Laurie, S.M., Odeny, D.A., Vorster, B.J., Mphela, W.M., Greyling, M.M., et al. 2016. Genetic analysis of yield and flesh colour in sweet potato. African Crop Science Journal 24(1):61-73. https://doi.org/10.4314/acsj.v24i1.5.

Nduwumuremyi, A., Melis, R., Shanahan, P., and Theodore, A. 2017. Interaction of genotype and environment effects on important traits of cassava (Manihot esculenta Crantz). Crop Journal 5(5):373-386. https://doi.org/10.1016/j.cj.2017.02.004.

Niringiye, C.S., Ssemakula, G., Namakula, J., Kigozi, C., Lajo, A., Mpembe, I., et al. 2014. Evaluation of promising sweet potato clones in selected agro ecological zones of Uganda. Time Journals of Agriculture and Veterinary Sciences 2(3):81-88.

Purchase, J. 1997. Parametric analysis to describe genotype $\mathrm{x}$ environment interaction and yield stability in winter wheat. University of the Free State, Bloemfontein, South Africa. http://scholar.ufs.ac.za:8080/xmlui/bitstream/handle/11660/1966/ PurchaseJL.pdf?sequence $=1 \&$ isAllowed $=\mathrm{y}$.

Roostaei, M., Mohammadi, R., and Amri, A. 2014. Rank correlation among different statistical models in ranking of winter wheat genotypes. Crop Journal 2(2-3):154-163. https://doi.org/10.1016/j.cj.2014.02.002.

Ruswandi, D., Anggia, E., Hastini, T., Suhada, A., Istifadah, N., Ismail, A., et al. 2008. Seleksi Hibrida Jagung DR Unpad Berdasarkan Stabilitas dan Adaptabilitas Hasil di Delapan Lokasi di Indonesia. Zuriat 19(1):71-85.

Sa'diyah, H., and Hadi, A.F. 2016. AMMI Model for yield estimation in multi-environment trials: A comparison to BLUP. Agriculture and Agricultural Science Procedia 9:163-169. https://doi.org/10.1016/j.aaspro.2016.02.113.

Tekalign, T. 2007. Genotype $\times$ environment interaction for root yield of elite sweet potato (Ipomoea batatas (L.) Lam.) genotypes. South African Journal of Plant and Soil 24(3):144-146. https://doi.org/10.1080/02571862.2007.10634797.

Thiyagu, D., Rafii, M.Y., Mahmud, T.M.M., Latif, M.A., Malek, M.A., and Sentoor, G. 2013. Genotype by environment assessment in sweetpotato as leafy vegetable using AMMI model. Pakistan Journal of Botany 45(3):843-852.

Tumuhimbise, R., Melis, R., Shanahan, P., and Kawuki, R. 2014. Genotype $\times$ environment interaction effects on early fresh storage root yield and related traits in cassava. Crop Journal 2(5):329-337. https://doi.org/10.1016/j.cj.2014.04.008.

Waluyo, B., Roosda, A.A., Istifadah, N., Ruswandi, D., and Karuniawan, A. 2015. Identification of fifty sweetpotato (Ipomoea batatas (L.) Lam.) promising clones for bioethanol raw materials. Energy Procedia 65:22-28. https://doi.org/10.1016/j. egypro.2015.01.024.

Yan, W., Kang, M.S., Ma, B., Woods, S., and Cornelius, P.L. 2007. GGE biplot vs. AMMI analysis of genotype-by-environment data. Crop Science 47(2):643-655. https://doi.org/10.2135/cropsci2006.06.0374.

Yan, W., and Tinker, N.A. 2006. Biplot analysis of multi-environment trial data: Principles and applications. Canadian Journal of Plant Science 86(3):623-645. https://doi.org/10.4141/P05-169. 